\title{
Magnetic nanoparticles as an effective adsorbent for removal of fluoride-a review
}

\begin{abstract}
Fluoride concentration more than $1.5 \mathrm{mg} / \mathrm{L}$ in drinking water can create various health issues and can lead to various human diseases. Adsorption is considered as one of the best technique for fluoride removal. Poor adsorption capacities, long contact time, high dosage, extremely low or high $\mathrm{pH}$ are the major drawbacks of various adsorption processes. In recent years several surface modified magnetic nanoparticles paves the way for effective removal of fluoride from water. The review fundamentally assesses the potential use of different surface modified magnetic nanoparticles (MNPs) for the effective removal of fluoride from contaminated water. High fluoride adsorption capacity of $91.04 \mathrm{mg} / \mathrm{g}$ at $\mathrm{pH}$ value of normal water is seen in case of $\mathrm{Ce}-\mathrm{Ti} @ \mathrm{Fe} 3 \mathrm{O} 4$ magnetic nanoparticle whereas the adsorption capacity of $\mathrm{Zr}$ based MNP is as high as $158 \mathrm{mg} / \mathrm{g}$ at very low water $\mathrm{pH}$. Interestingly, Fe3O4 encapsulated $\mathrm{Zr}$ (IV)-poly (acrylamide) magnetic nanomaterials exhibit very high fluoride adsorption capacity of $124.5 \mathrm{mg} / \mathrm{g}$ in normal water. Though the magnetic assistance makes the whole separation process easy in using magnetic material adsorbent, there are still challenges like reusability, toxicity regarding the material selection, environmental impact etc.
\end{abstract}

Keywords: fluoride, magnetic nanoparticles, water treatment, adsorption, defluoridation
Volume 3 Issue 3 - 2018

\author{
Sharma M,' Kalita P,' Garg A, ${ }^{3}$ Senapati KK ${ }^{4}$ \\ 'Centre for Rural Technology, Indian Institute of Technology \\ Guwahati, India \\ ${ }^{2}$ Centre for Energy, Indian Institute of Technology Guwahati, \\ India \\ ${ }^{3}$ Department of Civil and Environmental Engineering, Shantou \\ University, China \\ ${ }^{4}$ Central Instruments Facility, Indian Institute of Technology \\ Guwahati, India
}

\begin{abstract}
Correspondence: Senapati KK, Central Instruments Facility, Indian Institute of Technology Guwahati, Guwahati-781039, Assam, India, Tel +91-3612-583 I-03, Fax +91-3612-69310,
\end{abstract} Email kulasenapati@gmail.com

Received: December 21, 2017| Published: June 25, 2018

\section{Introduction}

The clean and affordable water is one of the basic needs of every human on this planet. The population is increasing day by day and hence the per capita water availability is decreasing. Rapid industrialization has also polluted the water. Use of chemical fertilizers to enhance the agriculture productivity in addition to using pesticides, herbicides in crop management are also among one of the major causes of water pollution. The spread of contaminants in to surface water and groundwater has become a serious issue. There are various contaminants in water polluting the water bodies such as organic, inorganic, heavy metals, microbial and radioactive species which may in different forms viz. suspended, dissolved, or dispersed materials. Fluoride is among one of the major water pollutants and responsible for various diseases. The fluoride content less than $1.5 \mathrm{mg} / \mathrm{L}$ has beneficial effect but exposure to high concentration can cause serious health hazards. ${ }^{1}$ The permissible limit of fluoride is $1.5 \mathrm{mg} / \mathrm{L}(\mathrm{WHO})^{2}$ in case of potable water. Defluoridation is the only option to overcome the problem of fluoride in drinking water. There are many processes for the defluoridation such as adsorption and ion exchange, coagulation and precipitation, membrane separation processes. ${ }^{2}$ Adsorption is considered as the one of the best technique for the removal of fluoride from drinking water, however it depends upon the adsorbent i.e. its adsorption capacity, contact time, dosage, change in $\mathrm{pH}$ value when added to water etc. Recent advancements in nanotechnology have opened the way for efficient treatment of water. There are various nanoparticle based products such as carbon nanotubes, nanoscale metal oxides, nanofibers, etc. used for water purification. ${ }^{3}$ The magnetic nanoparticles offer an advantage of surface modification for targeting a particular contaminant for adsorption as well as magnetic separation which make the whole process easy (Figure 1). The use of magnetic nanoparticles (magnetite $\mathrm{Fe}_{3} \mathrm{O}_{4}$ ) for separation of water pollutants has already been established in ground water remediation, in particular for the removal of arsenic. ${ }^{4}$ However, the use of magnetic nanoparticles and their surface functionalized composites have not been much studied in fluoride removal. There are different methods for the synthesis of magnetic nanoparticles such as co-precipitation, hydrothermal, solvochemical, micro-emulsion, sonochemical etc. Co-precipitation method is one of the simplest techniques to obtain magnetic nanoparticles. In this method a stoichiometric ratio of $\mathrm{Fe}^{2+}$ and $\mathrm{Fe}^{3+}$ is used as an iron source, which under suitable alkaline medium gives $\mathrm{Fe}_{3} \mathrm{O}_{4}$ magnetic nanoparticles. In this method of synthesis, the size, shape, composition of the synthesized nanoparticles depends upon the salt used, the stoichiometric ratio of $\mathrm{Fe}^{2+}$ and $\mathrm{Fe}^{3+}$, temperature, type of stabilizing agent, and $\mathrm{pH}$ value of the reaction media. ${ }^{5,6}$ In this method of synthesis, the reaction temperature is generally $20-90^{\circ} \mathrm{C} .{ }^{7}$ Hydrothermal method is generally used for the synthesis of single crystals of minerals in hot water under high pressure in an autoclave. ${ }^{8}$ It is different from the co-precipitation method because in this method in place of a stoichiometric mixture, one ferrous precursor is used. In this route of synthesis, the reaction temperature is normally $100-320^{\circ} \mathrm{C} .{ }^{9}$ Solvochemical method of synthesis is similar to hydrothermal synthesis, but an organic solvent is used as a dispersion media instead of water. Using solvochemical synthesis the morphology of the particles can be controlled to a large extent. Along with the advantage of morphology control, hydrophobic particles can also be yielded..$^{10}$ Micro emulsion method of synthesis can be used to prepare nanoparticles from two types of immiscible solvents in the presence of a surfactant. In this method different shapes of nanoparticles can be obtained. Micro emulsion can be used to obtain the uniform size, morphology, good disparity. Zhang et. al reported that using solvothermal analysis at $\mathrm{pH}=8.5$, a mixture of spherical particles and needle like rods can be obtained on the other hand at $\mathrm{pH}=10.5$, spherical nanoparticles can be obtained. ${ }^{11}$ 
Sonochemical method of synthesis uses the ultrasonic activation in the internal liquid to generate transient high temperature, high partial pressure also accompanied by micro-effects, such as shock waves, that can promote oxidation, reduction, decomposition and hydrolysis. In this method of synthesis, the size of the particle, shape, and magnetic behavior is dependent upon the ultrasonic frequency, sonicating duration, reaction temperature, etc. ${ }^{12}$ Herein, various types of magnetic nanomaterials in fluoride removal are addressed and their fluoride adsorption capacities are compared.

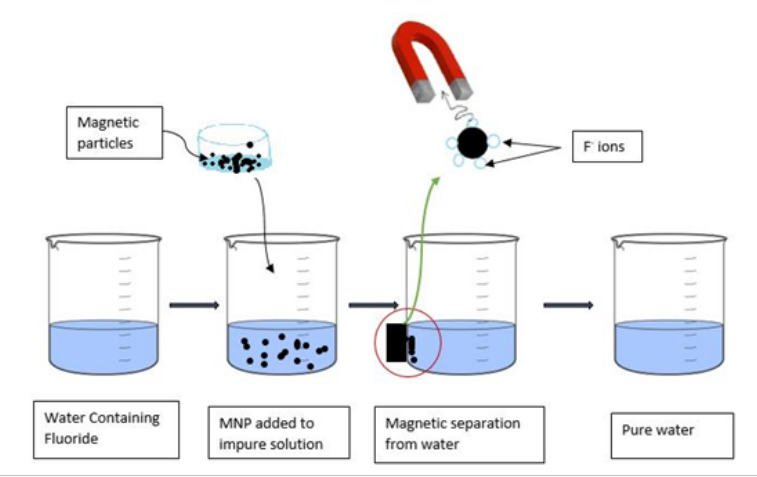

Figure I Schematic illustration of the defluoridation using MNPs.

\section{Discussion}

\section{Magnetic nanoparticles for fluoride removal}

Magnetic nanoparticles have large surface area; high reactivity, specificity, and self-assembly make them different from common adsorbents. A number of magnetic nanoparticles were synthesized for fluoride removal. Markeb et al., ${ }^{13}$ synthesized $\mathrm{Ce}-\mathrm{Ti} @ \mathrm{Fe}_{3} \mathrm{O}_{4}$ nanoparticles for fluoride removal. They found the maximum adsorption capacity of $91.04 \mathrm{mg} / \mathrm{g}$ at $\mathrm{pH} 7$ and also showed a fast adsorption rate. They also observed that it can be used for 5 cycles without significant loss of adsorption capacity. Similarly, Zhao et al., ${ }^{14}$ synthesized $\mathrm{Fe}_{3} \mathrm{O}_{4} @ \mathrm{Al}(\mathrm{OH})_{3}$, nanoparticles which combines the advantages of magnetic separation and aluminum oxide has a high affinity towards fluoride.

$$
\mathrm{Al}(\mathrm{OH})_{3}+x F^{-1} \rightarrow \mathrm{Al}(\mathrm{OH})_{3-x} \mathrm{~F}_{x}+\mathrm{OH}-
$$

Riahi et al., ${ }^{15}$ synthesizedFe $\mathrm{O}_{4}$ magnetic nanoparticles modified with zirconia $\left(\mathrm{ZrO}_{2}\right)$ using co-precipitation method and calculated the adsorption capacity using Langmuir equation and it was found to be $158.6 \mathrm{mg} / \mathrm{g}$ at $\mathrm{pH}$ 2.5. Zhang et al., ${ }^{16}$ synthesized $\mathrm{Fe}_{3} \mathrm{O}_{4}$ magnetic nanoparticles coated with $\mathrm{Fe}-\mathrm{Ti}$ bimetallic oxide by co-precipitation method and found that saturation adsorption capacity of $57.22 \mathrm{mg} / \mathrm{g}$. They also found that adsorption was fast and equilibrium reached in 2 minutes. They further used this bimetallic magnetic composite nano adsorbent $\left(\mathrm{Fe}_{3} \mathrm{O}_{4} @ \mathrm{Fe}-\mathrm{Ti}\right)$ in a fluidized bed system for fluoride removal. ${ }^{17}$ Asgari et al., ${ }^{18}$ synthesized $\mathrm{Fe}_{3} \mathrm{O}_{4}$ magnetic nanoparticles and modified the surface with 3-aminopropyltriethoxysilane and a $\mathrm{Ga}$ (III) porphyrin complex, Ga (TCPP) $\mathrm{Cl}_{2}$ [TCPP: tetrakis (4carboxyphenyl) porphyrin]. They tested the sample for fluoride adsorption and found that fluoride with an initial concentration of 10 $\mathrm{mg} / \mathrm{L}$ was reduced to $0.3 \mathrm{mg} / \mathrm{L}$ in contact time of 30 minutes. They also tested the reusability and they found that removal efficiency of fluoride in 5 cycles reduced from $97.2 \%$ to $87 \%$.
Liu et al., ${ }^{19}$ synthesized iron aluminum oxide magnetic nanoparticles anchored on graphene oxide (IAO/GO). They found that $\mathrm{IAO} / \mathrm{GO}$ exhibits super paramagnetism, good selectivity for fluoride, high adsorption capacity and good acid alkali stability. They found the maximum sorption capacity from Langmuir model was $64.72 \mathrm{mg} / \mathrm{g}$. They also concluded that the IAO/GO can be applied for defluoridation of natural water environments because of its good selectivity for fluoride removal when co-anions exist, good removal efficiency, and low residual iron and aluminum concentration after defluoridation. They explained that electrostatic interactions, ion exchange and inner-sphere complexations were the main factors of adsorption mechanisms. Azari et al., ${ }^{20}$ synthesized iron-silver magnetic binary oxide nanoparticles using co-precipitation method for removal of fluoride from aqueous solution. They found the adsorption capacity of $22.88 \mathrm{mg} / \mathrm{g}$ and the maximum adsorption was observed at $\mathrm{pH} 3$ and the equilibrium was reached within 20 minutes. Yang et al., ${ }^{21}$ synthesized magnetic alumina aerogel for the removal of fluoride from water. In their process, magnetic alumina hydrogel adsorbent was fabricated by amending alumina aerogel with $\mathrm{Fe}_{3} \mathrm{O}_{4}$. They found the adsorption capacity of $32.1 \mathrm{mg} / \mathrm{g}$ at $\mathrm{pH} 5.0$. They also tested it for fluoride removal from well water. They reported that the as prepared magnetic alumina aerogel was an effective and easily prepared adsorbent and was easily separable after adsorption.

Chang et al.,22 prepared $\mathrm{Mg}-\mathrm{Al}$ layered double hydroxides magnetic composites for removal of fluoride from aqueous solution using ultrasound assisted co-precipitation method. The prepared composite showed the high adsorption capacity of fluoride i.e. is $47.7 \mathrm{mg} / \mathrm{g}$. They also showed that ultrasound irradiation assistance increases the specific surface are and reduces the size of the nanocomposite. Srivastava et al., ${ }^{23}$ synthesized the magnetic nickel/ polypyrrole nanostructures and found that it exhibits excellent adsorption capacity for fluoride and arsenic. They found the adsorption capacity for fluoride to be $67.71 \mathrm{mg} / \mathrm{g}$. Bandpiet al., ${ }^{24}$ synthesized chitosan impregnated $\mathrm{Fe}_{3} \mathrm{O}_{4}$ nanoparticles using chemical co-precipitation method. The maximum fluoride uptake of the linear polysaccharide coated magnetic nanocomposite ( $\mathrm{Fe}_{3} \mathrm{O}_{4}$-chitosan) was $9.43 \mathrm{mg} / \mathrm{g}$. They also suggested that $\mathrm{Fe}_{3} \mathrm{O}_{4}$-chitosan can be easily reused for at least five successive cycles while maintaining the high adsorption capacity. Gao et al., ${ }^{25}$ synthesized $\mathrm{Mg}-\mathrm{Al}$-layered double hydroxides $(\mathrm{Mg}-\mathrm{Al}-\mathrm{LDH})$ nanoflake impregnated magnetic alginate beads and evaluated defluoridation performance. They showed that the $\mathrm{Mg}-\mathrm{Al}-\mathrm{LDH}$ magnetic nanocomposites have high adsorption capacity and the bio-based (alginate) sorbents offers advantages of biodegradability, hydrophilic properties etc. They also tested for fluoride removal from real groundwater samples and they reported the feasibility of fluoride removal from contaminated groundwater. Wen et al., ${ }^{26}$ synthesized three component nanomagnetite adsorbent $(\gamma-$ $\mathrm{Fe}_{3} \mathrm{O}_{4}$-graphite-La) for fluoride adsorption. They found the maximum adsorption capacity of $77.12 \mathrm{mg} / \mathrm{g}$ at $25^{\circ} \mathrm{C}$ and $\mathrm{pH}=7 \pm 0.1$. Bhaumiket al. ${ }^{27}$ synthesized polypyrrole/ $/ \mathrm{Fe}_{3} \mathrm{O}_{4}$ magnetic nanocomposites similar to the $\mathrm{Ni}$ /polypyrrole nanocomposite for fluoride removal and found the adsorption capacity for fluoride within the range of 17.63-22.31 $\mathrm{mg} / \mathrm{g}$ at $\mathrm{pH}$ 6.5. They reported that the magnetic adsorbent retained the original adsorption capacity after one complete adsorptiondesorption cycle and was reusable in fluoride removal from water. Kumariet al., ${ }^{28}$ worked over the development of a cost-effective, portable, environment and user-friendly defluoridation technique. They developed the $\mathrm{Fe}_{3} \mathrm{O}_{4}$ nanoparticles impregnated on to the polyurethane foam $\left(\mathrm{Fe}_{3} \mathrm{O}_{4} @ \mathrm{PUF}\right)$ and made into tea infusion bags. 
They obtained the defluoridation capacity of $\mathrm{Fe}_{3} \mathrm{O}_{4} @$ PUF to be $34.48 \mathrm{mg} / \mathrm{g}$ for fluoride.

Poursaberi et al., ${ }^{29}$ synthesized 3-aminopropyltriethoxysilane (APTES) coated magnetic nanoparticles functionalized with a zirconium (IV) porphyrin complex, $\mathrm{Zr}$ (TCPP) $\mathrm{Cl}_{2}$ [TCPP: tetrakis (4-carboxyphenyl) porphyrin]. They found the fluoride adsorption capacity of $92 \pm 1.7 \%$ in contact time of 20 minutes at $\mathrm{pH} 5.5$. Thakur et al., ${ }^{30}$ synthesized super paramagnetic Zirconium (IV)polyacrylamide/ $\mathrm{Fe}_{3} \mathrm{O}^{4}$ magnetic composites and found a very high fluoride adsorption capacity of $124.5 \mathrm{mg} / \mathrm{g}$ from natural water. Kumar et. al., ${ }^{31}$ synthesized bimetal doped micro and nano adsorbent for removal of fluoride and found high fluoride adsorption capacity of $100 \mathrm{mg} / \mathrm{g}$. Chai et al., ${ }^{32}$ developed sulfate-doped $\mathrm{Fe}_{3} \mathrm{O}_{4} / \mathrm{Al}_{2} \mathrm{O}_{3}$ magnetic nanoparticles for the removal of fluoride from drinking water. He found the adsorption capacity of the nannoadsorbent to be $70 \mathrm{mg} / \mathrm{g}$ at $\mathrm{pH} 7$. Interestingly he found that the performance of nannoadsorbent was good at a wide range of $\mathrm{pH} 4-10$. Ma et al., ${ }^{33}$ synthesized and studied the characteristics of equilibrium, adsorption of fluoride on magnetic-chitosan particle and he found the adsorption to be $20.93-23.98 \mathrm{mg} / \mathrm{g}$. Wan et al., ${ }^{34}$ synthesized $\gamma-\mathrm{AlOOH} @ \mathrm{CS}$ (pseudoboehmite and chitosan shell) magnetic nanoparticles for the removal of fluoride from drinking water. They observed that $80 \%$ of the adsorption took place within initial 20 minutes and equilibrium was reached in 60 minutes. They also found the maximum adsorption capacity of $67.5 \mathrm{mg} / \mathrm{g}$ at $20^{\circ} \mathrm{C}$ and $\mathrm{pH}=7 \pm 0.1$. Dong et al., ${ }^{35}$ developed a lanthanum loaded magnetic cationic hydrogel for the adsorption of fluoride from drinking water. They found the adsorption capacity reached to $93 \%$ of the ultimate adsorption capacity in the initial 10 minutes. They also found the maximum adsorption capacity of $136.78 \mathrm{mg} / \mathrm{g}$. Chang et al., ${ }^{36}$ synthesized super paramagnetic zirconia material for the adsorption of fluoride. They found that as the $\mathrm{pH}$ decreases the fluoride adsorption capacity of the material increases. They found the adsorption capacity of $14.7 \mathrm{mg} / \mathrm{g}$ at $\mathrm{pH} 4$. Mohan et al., ${ }^{37}$ synthesized magnetic and nonmagnetic corn stoverbiochar for the adsorption of fluoride and they found that the maximum adsorption takes place at $\mathrm{pH} 2.0$. They performed the adsorption study at $25^{\circ}$, $35^{\circ}$, and $45^{\circ}$ and found the maximum adsorption of $5.17 \mathrm{mg} / \mathrm{g}$ at $35^{\circ} \mathrm{C}$. Zhang et al., ${ }^{38}$ synthesized the $\mathrm{Fe}_{3} \mathrm{O}_{4} @ \mathrm{Ag}-$ La magnetic nanoparticles using elecro-extrusion method for fluoride removal. They found the maximum adsorption capacity of $45.320 \mathrm{mg} / \mathrm{g}$ at $\mathrm{pH} 4$. They also found that other ions such as $\mathrm{Cl}^{-}, \mathrm{SO}_{4}{ }^{2-}, \mathrm{HCO}_{3-}$ and $\mathrm{PO}_{4}{ }^{3-}$ has almost no effect on fluoride adsorption.

\section{Conclusion}

In this review, different type of magnetic nanoparticles for the removal of fluoride has been discussed which is depending upon their adsorption capacities, contact time, dosage, pH etc. Ce-Ti@ $\mathrm{Fe}_{3} \mathrm{O}_{4}$ nanoparticles were reported to the maximum adsorption capacity for fluoride removal at $\mathrm{pH}$ value of 7 . With a little surface modification, the targeted contaminant can be effectively removed with these MNPs. Magnetic nanoparticles are already being used for the removal of heavy metal from wastewater. The review also showed that coating with some green organic material can also be used for adsorption of contaminants. Therefore, it can be concluded that magnetic nanoparticles have a huge potential for water treatment processes.

\section{Acknowledgements}

None.

\section{Conflict of interest}

The author declares there is no conflict of interest.

\section{References}

1. Fawell J, Bailey K, Chilton J. Fluoride in Drinking-water. Iwa Publishing; 2013.

2. Kumar M, Puri A. A review of permissible limits of drinking water. Indian J Occup Environ Med. 2012;16(1):40-44.

3. Ministry of Drinking Water and Sanitation. Handbook on Drinking Water Treatment Technologies. National Environmental Engineering Research Institute. India; 2011.

4. Overview and comparison of various conventional and nano based water treatment technologie. India; 2006.

5. Gehrke Ilka, Andreas Geiser, Annette Somborn-Schulz. Innovations in nanotechnology for water treatment. Nanotechnol Science App. 2015;(8):1-17.

6. Laurent S, Forge D, Port $\mathrm{M}$, et al. Magnetic iron oxide nanoparticles: synthesis,stabilization, vectorization, physicochemical characterizations, and biological applications. Chem Rev. 2008;108:2064-2110.

7. Gupta, Ajay Kumar, Mona Gupta. Synthesis and surface engineering of iron oxide nanoparticles for biomedical applications. Biomaterials. 2005;26(18):3995-4021.

8. Fan R, Chen XH, Gui Z, et al. A new simple hydrothermal preparation of nanocrystalline magnetite $\mathrm{Fe}_{3} \mathrm{O}_{4}$. Materials Research Bulletin. 2001;36(3-4):497-502.

9. Demirer GS, Okur AC, Kizilel S. Synthesis and design of biologically inspired biocompatible iron oxide nanoparticles for biomedical applications. Journal of Materials Chemistry B. 2015;3(40):78317849.

10. Hyeon T, Lee SS, Park J, et al. Synthesis of highly crystalline and monodisperse maghemitenanocrystallites without a size-selection process. J Am Chem Soc. 2001;123(51):12798-12801.

11. Zhou ZH, Wang J, Liu X, et al. Synthesis of $\mathrm{Fe}_{3} \mathrm{O}_{4}$ nanoparticles from emulsions. Journal of Materials Chemistry. 2001;11(6):1704-1709.

12. Mukh-Qasem RA, Gedanken A. Sonochemical synthesis of stable hydrosol of $\mathrm{Fe}_{3} \mathrm{O}_{4}$ nanoparticles. Journal of colloid and interface science. 2005;284(2):489-494.

13. Markeb AA, Alonso A, Sánchez A, et al. Adsorption process of fluoride from drinking water with magnetic core-shell Ce-Ti@ Fe $3 \mathrm{O} 4$ and Ce-Ti oxide nanoparticles. Sci Total Environ. 2017;598:949-958.

14. Zhao X, Wang J, Wu F, et al. Removal of fluoride from aqueous media by $\mathrm{Fe}_{3} \mathrm{O}_{4} @ \mathrm{Al}(\mathrm{OH})_{3}$ magnetic nanoparticles. J Hazard Mater. 2010;173(1):102-109.

15. Riahi F, Bagherzadeh M, Hadizadeh Z. Modification of $\mathrm{Fe}_{3} \mathrm{O}_{4}$ super paramagnetic nanoparticles with zirconium oxide; preparation, characterization and its application toward fluoride removal. RSC Advances. 2015;5(88):72058-72068.

16. Zhang $\mathrm{C}$, Li Y, Wang TJ, et al. Adsorption of drinking water fluoride on a micron-sized magnetic $\mathrm{Fe}_{3} \mathrm{O}_{4} @ \mathrm{Fe}-\mathrm{Ti}$ composite adsorbent. Applied Surface Science. 2016;363:507-515.

17. Zhang C, Li Y, Wang TJ, et al. Size-Dependent Fluoride Removal Performance of a MagneticFe $\mathrm{O}_{3} @ \mathrm{Fe}-\mathrm{Ti}$ Adsorbent and Its Defluoridation in a Fluidized Bed. Industrial \& Engineering Chemistry Research. 2017;56(9):2425-2432. 
18. Asgari B, Bowen J. Gallium (III)-metalloporphyrin grafted magnetite nanoparticles for fluoride removal from aqueous solutions. Natural Products Chemistry \& Research. 2017;11:5(5).

19. Liu L, Cui Z, Ma Q, et al. One-step synthesis of magnetic ironaluminum oxide/graphene oxide nanoparticles as a selective adsorbent for fluoride removal from aqueous solution. RSC Advances. 2016;6(13):10783-10791.

20. Azari A, Kalantary RR, Ghanizadeh G, et al. Iron-silver oxide nanoadsorbent synthesized by co-precipitation process for fluoride removal from aqueous solution and its adsorption mechanism. RSC Advances. 2015;5(106):87377-87391.

21. Yang W, Dou X, Li Y, et al. Performance and mass transfer of aqueous fluoride removal by a magnetic alumina aerogel. RSC Advances. 2016;6(114):112988-112999.

22. Chang Q, Zhu L, Luo Z, et al. Sono-assisted preparation of magnetic magnesium-aluminum layered double hydroxides and their application for removing fluoride. Ultrasonics Sonochemistry. 2011;18(2):553-561.

23. Srivastava SK, Senapati S, Singh SB, et al. Magnetic Ni/PPy nanocomposite as effective reusable adsorbent for removal of arsenite and fluoride from contaminated water. RSC Advances. 2016;6(114):113424-113431.

24. Mohseni-Bandpi A, Kakavandi B, Kalantary RR, et al. Development of a novel magnetite-chitosan composite for the removal of fluoride from drinking water: adsorption modeling and optimization. RSC Advances. 2015;5(89):73279-73289.

25. Gao C, Yu XY, Luo T, et al. Millimeter-sized Mg-Al-LDH nanoflake impregnated magnetic alginate beads ( $\mathrm{LDH}-\mathrm{n}-\mathrm{MABs}$ ): a novel biobased sorbent for the removal of fluoride in water. Journal of Materials Chemistry A. 2014;2(7):2119-2128.

26. Wen S, Wang Y, Dong S. Performance and characteristics of fluoride adsorption using nanomagnetite graphite-La adsorbent. RSC Advances. 2015;5(109):89594-89602.

27. Bhaumik M, Leswifi TY, Maity A, et al. Removal of fluoride from aqueous solution by polypyrrole $/ \mathrm{Fe}_{3} \mathrm{O}_{4}$ magnetic nanocomposite. Journal of hazardous materials. 2011;186(1):150-159.

28. Kumari S, Khan S. Defluoridation technology for drinking water and tea by green synthesized $\mathrm{Fe}_{3} \mathrm{O}_{4} / \mathrm{Al}_{2} \mathrm{O}_{3}$ nanoparticles coated polyurethane foams for rural communities. Scientific Reports. 2017;7(1):8070.

29. Poursaberi T, Hassanisadi M, Torkestani K, et al. Development of zirconium (IV)-metalloporphyrin grafted $\mathrm{Fe}_{3} \mathrm{O}_{4}$ nanoparticles for efficient fluoride removal. Chemical Engineering Journal. 2012;189190:117-125.

30. Thakur N, Kumar SA, Parab H, et al. A fluoride ion selective $\mathrm{Zr}$ (IV)-poly (acrylamide) magnetic composite. RSC Advances. 2014;4(20):10350-10357.

31. Kumar V, Talreja N, Deva D, et al. Development of bi-metal doped micro-and nano multi-functional polymeric adsorbents for the removal of fluoride and arsenic (V) from wastewater. Desalination. 2011;282:27-38

32. Chai L, Wang $\mathrm{Y}$, Zhao $\mathrm{N}$, et al. Sulfate-doped $\mathrm{Fe}_{3} \mathrm{O}_{4} / \mathrm{Al}_{2} \mathrm{O}_{3}$ nanoparticles as a novel adsorbent for fluoride removal from drinking water. Water research. 2013;47(12):4040-4049.

33. Ma W, Ya FQ, Han M, et al. Characteristics of equilibrium, kinetics studies for adsorption of fluoride on magnetic-chitosan particle. Journal of Hazardous Materials. 2007;143(1-2):296-302.

34. Wan Z, Chen W, Liu C, et al. Preparation and characterization of $\gamma-\mathrm{AlOOH}$ @ CS magnetic nanoparticle as a novel adsorbent for removing fluoride from drinking water. J Colloid Interface Sci. 2015; 443:115-124.

35. Dong S, Wang Y. Characterization and adsorption properties of a lanthanum-loaded magnetic cationic hydrogel composite for fluoride removal. Water research. 2016;88:852-860.

36. Chang CF, Chang CY, Hsu TL. Removal of fluoride from aqueous solution with the super paramagnetic zirconia material. Desalination. 2011;279(1-3):375-382.

37. Mohan D, Kumar S, Srivastava A. Fluoride removal from ground water using magnetic and nonmagnetic corn stoverbiochars. Ecological Engineering. 2014;73:798-808.

38. Zhang $\mathrm{Y}$, Lin $\mathrm{X}$, Zhou Q, et al. Fluoride adsorption from aqueous solution by magnetic core-shell $\mathrm{Fe}_{3} \mathrm{O}_{4} @$ alginate-La particles fabricated via electro-co extrusion. Applied Surface Science. 2016;389:34-45. 